\title{
Analysis of diesel soot derived from the use of butanol blends in a Euro 6 diesel engine
}

\author{
Authors: Magín Lapuerta ${ }^{1}$, Jesús Sanchez-Valdepeñas ${ }^{1}$, Javier Barba Salvador ${ }^{1}$, David Fernández \\ Rodríguez ${ }^{1}$, Juan Pedro Andrés ${ }^{1}$, Tomás García ${ }^{2}$ \\ ${ }^{1}$ Escuela Técnica Superior de Ingenieros Industriales. Universidad de Castilla - La Mancha. Avda. \\ Camilo José Cela s/n. 13071 Ciudad Real, Spain. \\ ${ }^{2}$ Instituto de Carboquímica, ICB-CSIC, Miguel Luesma Castán 4, 50018, Zaragoza, Spain.
}

Corresponding Author:

Magín Lapuerta

E-mail: Magin.Lapuerta@uclm.es

Telephone: +(34) 926295431

Fax: +(34) 926295361

\begin{abstract}
The use of advanced fuels must increase from 0.5 to 3.6 in internal combustion engines according to the forthcoming European directive. In this frame, alcohols that can be obtained from waste or lignocellulosic materials with advanced production techniques may play an important role in the future. This work focuses on the effect of the use of butanol as a blend component on the properties of soot emmited from compression ignition engines. This knowledge is essential to decide the strategy to carry out a proper regeneration process in the Diesel Particle Filter (DPF). The study was performed in a Euro 6 diesel engine. The engine operating condition used to collect particulate matter was selected as a typical steady mode in urban driving. The blends tested were baseline diesel, Bu10D (10\% butanol and 90\% diesel v/v), Bu20D (20\% butanol and 80\% diesel v/v) and Bu10B10D (10\% butanol, 10\% biodiesel and 80\% diesel $\mathrm{v} / \mathrm{v})$. The techniques used to characterise the soot are X-Ray Difraction (XRD), Raman spectroscopy, Transmission Electron Microscopy (TEM), surface area analyser, X-ray Photoelectron Spectroscopy (XPS), Fourier-Transform Infrared Spectroscopy (FTIR), Thermogravimetric Analysis (TGA) and Differential Scanning Calorimetry (DSC). From the results shown, the average primary particle diameter, which is reduced for increasing butanol content, provided the best consistency with soot reactivity obtained from TGA and DSC.
\end{abstract}

\section{Introduction}

Today, the most important issue related to the use of vehicles is pollutant emissions, which have direct effect on human health ${ }^{1}$ and environment ${ }^{2}$. Nowadays, climatic change, mainly produced as a consequence of global warming, has been pointed out as one of the most important environmental problem. Carbon dioxide $\left(\mathrm{CO}_{2}\right)$ emissions emitted from vehicles have been highlighted as one of the main contributors to global warming ${ }^{3}$. Diesel engines, due to their higher efficiency, emit less $\mathrm{CO}_{2}$ than spark ignition engines but, on the contrary, the use of diesel engines is usually associated with nitrogen oxides $\left(\mathrm{NO}_{\mathrm{x}}\right)$ and particulate matter $(\mathrm{PM})$ emissions.

To reduce the emissions adverse effect, more and more stringent standards have been implemented all over the world. In Europe, from 2014, light diesel vehicles must fulfil Euro 6 standard ${ }^{4}$, which set strict limits for $\mathrm{NO}_{\mathrm{x}}$ and particulate emissions. One of the strategies to reduce pollutant emissions is the use of first-generation biofuels and advanced fuels to replace, at least partially, fossil fuels. Although biodiesel is the most used biofuel in road transport, the new directive RED-II supports the use of advanced biofuels, such as alcohols, to the detriment of first-generation biofuels. Although ethanol has been often used as a fuel component in diesel vehicles ${ }^{6,7}, \mathrm{n}$-butanol has better properties (higher cetane number, heating value, viscosity and lower flash point $)^{8,9}$. Additionally, n-butanol can be considered as an advanced biofuel as far as it can be produced from waste or lignocellulosic materials ${ }^{10-12}$. Currently, butanol can be produce through ABE (acetone-n-butanol-ethanol) or IBE (isopropanol-n-butanol-ethanol) fermentation ${ }^{10,13}$. 
Another strategy to reduce pollutant emissions is the use of different aftertreatment systems to fulfil with the standards. In current diesel engines, nitrogen oxides emissions are reduced in $\mathrm{NO}_{\mathrm{x}}$ aftertreatment systems $^{14}$, such as LNT (Lean $\mathrm{NO}_{\mathrm{x}}$ Trap) or SCR (Selective Catalytic Reduction). On the other hand, particulate emissions are trapped in particulate filter (DPF) to be subsequently eliminated in an oxidation process, known as regeneration process. This process is affected by different factors like exhaust gas composition, temperature and flow rate, filter characteristics, temperature and flow profiles through the filter channels, and physicochemical properties of soot ${ }^{15,16}$. The study of soot characteristics and its implications on soot oxidation process could reduce the adverse effect of the regeneration process on fuel consumption and on filter lifetime.

Soot properties have been analyzed with different analysis techniques (nanostructural, chemical and thermal). Among the nanostructural analysis techniques highlight X-ray diffraction (XRD) ${ }^{15,17}$, Raman spectroscopy ${ }^{18,19}$, transmission electron microscopy (TEM) ${ }^{20,21}$ or electron energy loss spectroscopy $(E E L S)^{22,23}$. Some researchers have tried to relate soot nanostructure with its reactivity, but consistent conclusions have rarely been reached. Soot reactivity is defined hereinafter as the soot ability to be oxidized under lower temperatures or at higher rates. As a rule, it is accepted in the literature ${ }^{22,24}$ that as the distance between carbon layers increases and the fringe length decreases, the soot surface is more prone to be oxidized, due to the weaker binding energy between planes and to the higher availability of carbon atoms at the edge site, respectively. A characteristic which could have a great impact on the soot reactivity is the primary particle size, which is inversely related to both the soot surface area and the oxygen accessibility to the carbonaceous substrate ${ }^{21}$. Different authors have also studied the functional groups adsorbed in soot surface with chemical analytical techniques such as those based in infrared spectroscopy (FTIR, DRIFTS or ATR $)^{25-27}$, X-ray photoelectron spectroscopy (XPS) ${ }^{28,29}$, energy dispersive spectroscopy $(\mathrm{EDS})^{30,31}$, nuclear magnetic resonance $(\mathrm{NMR})^{32,33}$ or near edge $\mathrm{X}$-ray absorption fine structure (NEXAFS) ${ }^{25,34}$. Many studies have investigated the oxygenated and aliphatic compounds on soot surface, since they are supposedly related to the soot reactivity ${ }^{16,25,35}$. Finally, in other investigations, soot has been analyzed with thermal analytical techniques. In these studies thermogravimetric analysis (TGA) or differential scanning calorimetry (DSC), among other techniques, have been used to assess soot reactivity, by quantifying either the temperature required by soot to be oxidized (subjected to a heating ramp) ${ }^{15,35}$ or the time needed to be oxidized (when subjected to an isotherm process $)^{16,28}$.

Finally, it is necessary to remark that obtaining conclusions about soot reactivity based on structural or chemical analysis results can lead to misleading conclusions. For this reason, to study the impact of soot characteristics on reactivity, a complete soot characterization at different levels (nano and microstructure, morphology, porosity, surface area and functional groups) is proposed in this work.

\section{Experimental setup}

\subsection{Engine and operation mode}

This study was carried out in a Euro 6 Nissan $1.5 \mathrm{dCi}$ engine (model K9K). This engine is a four-cylinder, four-stroke, turbocharged, intercooled, common-rail direct-injection diesel engine, and it is equipped with double exhaust gas recirculation system (EGR), with cooled low-pressure EGR (LPEGR) and non-cooled high pressure EGR (HPEGR). The aftertreatment system comprises a diesel oxidation catalyst (DOC), a Lean $\mathrm{NO}_{x}$ Trap (LNT) and a regenerative wall-flow-type diesel particle filter (DPF). The main characteristics of the engine are shown in Table 1.

Table 1: Diesel engine characteristics.

\begin{tabular}{|c|c|}
\hline Fuel injection system & DI, common rail \\
\hline Cylinders & 4 \\
\hline Valves per cylinder & 2 \\
\hline Bore $(\mathrm{mm})$ & 76 \\
\hline Stroke $(\mathrm{mm})$ & 80.5 \\
\hline Compression ratio & $15.5: 1$ \\
\hline Displacement $\left(\mathrm{cm}^{3}\right)$ & 1461 \\
\hline Maximum power $(\mathrm{kW})$ & $81 \mathrm{~kW} @ 4000 \mathrm{rpm}$ \\
\hline Maximum torque $(\mathrm{Nm})$ & $260 \mathrm{Nm} @ 1750-2500 \mathrm{rpm}$ \\
\hline
\end{tabular}

A rotating shaft was used to couple the engine to an asynchronous electric dynamometer (Schenck Dynas III LI 250), which controls the engine speed and torque. INCA PC software and ETAS ES 591.1 
hardware were used for the communication and management of the electronic control unit (ECU) of the engine. The inlet air mass flowrate and the fuel consumption were measured with the internal engine sensors and registered with the INCA PC software. Through the communication between the ECU and the INCA PC it is possible to perform the test with the different fuels under the same operative conditions (injection pressure, EGR valve position and injection position).

In order to collect soot, the gas flows through a $47 \mathrm{~mm}$ diameter filter with $1 \mu \mathrm{m}$ thickness. The filters, placed in a filter holder, have a retention efficiency of $99.99 \%$ and include a teflon membrane on a polymethylpentene ring in order to increase the rigidity. A vacuum pump sucks the gas though the filter. The filter is then scrapped and the particulate matter is collected for analysis. Finally, soot samples were analysed with different techniques, which will be described in section 2.3. Figure 1 shows a scheme of the engine installation where the soot collection system and the thermophoretic sampling are highlighted with purple lines.

The operation mode selected is illustrative of urban driving conditions and it represents an acceleration from $15 \mathrm{~km} / \mathrm{h}$ to $32 \mathrm{~km} / \mathrm{h}$. This engine condition reproduces a low load operation mode characterized by its high emission of particulate matter, resulting in a high contribution to the DPF loading, and because its relative low exhaust temperature, which prevents from spontaneous regeneration of soot in the DPF. The main characteristics of this operation mode are shown in Table 2.

Table 2: Engine operation mode characteristics

\begin{tabular}{|c|c|}
\hline Measured variables & Operation mode \\
\hline Engine speed $(\mathrm{rpm})$ & 1521 \\
\hline Effective torque $(\mathrm{Nm})$ & 66 \\
\hline Air flow $(\mathrm{kg} / \mathrm{h})$ & 56 \\
\hline Start of main injection $\left({ }^{\circ} \mathrm{CA}\right.$ bTDC) & 2.82 \\
\hline Start of pilot 1 injection $\left({ }^{\circ} \mathrm{CA}\right.$ aTDC) & 3.88 \\
\hline Start of pilot 2 injection $\left({ }^{\circ} \mathrm{CA}\right.$ aTDC) & 16 \\
\hline Fuel injected during pilot 1 injection $(\mu \mathrm{L} / \mathrm{inj})$ & 1.12 \\
\hline Fuel injection during pilot 2 injection $(\mu \mathrm{L} / \mathrm{inj})$ & 1.10 \\
\hline Injection pressure $(\mathrm{bar})$ & 550 \\
\hline
\end{tabular}




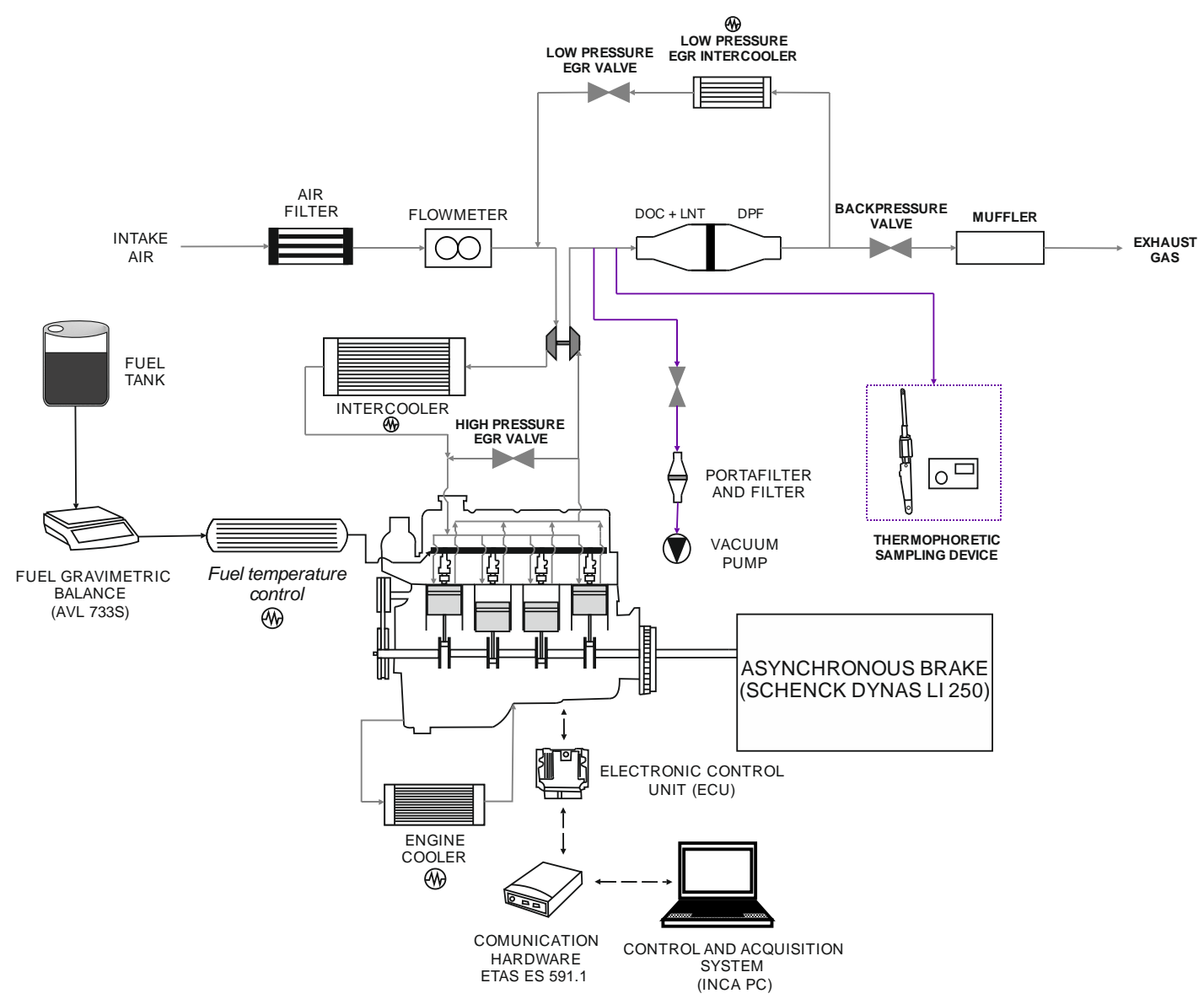

Figure 1: Scheme of the experimental installation.

\subsection{Fuels}

In this study, diesel blends with 10 and $20 \% \mathrm{v} / \mathrm{v}$ of n-butanol content (Bu10D and Bu20D, respectively) were tested. Bu10D blend was selected since the well-known 20-20-20 target forces to 10\% of the energy in the transport sector comes from renewable fuels ${ }^{36}$. Besides, n-butanol is considered an advanced fuel (since it is produced through an acetone-n-butanol-ethanol (ABE) fermentation process), whose contribution to the transport sector in energy basis will increase from $0.5 \%$ to $3.6 \%$ in the future European Regulations ${ }^{5}$. The other blend (Bu20D) has also been selected considering future regulations, in which an increase in renewable fuels is expected. Higher n-butanol contents were discarded because the low cetane number and the high enthalpy of vaporization of n-butanol would lead to cold start problems as confirmed in the work of Lapuerta et al. ${ }^{37}$. Finally, a ternary blend (Bu10B10D) composed of biodiesel (10\% v/v), nbutanol $(10 \% \mathrm{v} / \mathrm{v})$ and diesel $(80 \% \mathrm{v} / \mathrm{v})$ has also been selected considering that first generation biofuels and advanced fuels will coexist in the next years.

The diesel fuel used in this study was supplied by the Spanish oil company Repsol. It has no oxygen content and was similar to many diesel fuels supplied by petrol stations in Europe in winter. The biodiesel fuel used was donated by the Spanish biodiesel company Bio Oils and was produced from soybean (around $80 \% \mathrm{w} / \mathrm{w}$ ) and palm oils (around 20\% w/w). The content in saturated esters amounted to $20.64 \%$ $\mathrm{w} / \mathrm{w}$, which is not far from an average saturation content of biodiesel fuels produced in Europe. Butanol was supplied by Green Biologics Ltd., as a member of the Consortium of ButaNexT Project. The main properties and reference standard methods of pure fuels and blends tested are shown in Table 3.

Table 3: Main properties of tested fuels.

\begin{tabular}{|c|c|c|c|c|c|c|c|}
\hline Properties & Method & Diesel & Biodiesel & Butanol & Bu10D & Bu20D & Bu10B10D \\
\hline $\begin{array}{c}\text { Density at 15 } \\
\mathbf{( k g}^{\mathbf{}} \mathbf{C}\end{array}$ & EN ISO 3675 & 842.0 & 883.5 & 811.5 & 836.5 & 833.5 & 841 \\
\hline $\begin{array}{c}\text { Kinematic } \\
\text { viscosity at 40 } \\
\text { (cSt) }\end{array}$ & EN ISO 3104 & 3 & 4.19 & 2.27 & 2.61 & 2.51 & 2.73 \\
\hline $\begin{array}{c}\text { Lower heating } \\
\text { value (MJ/kg) }\end{array}$ & UNE 51123 & 42.93 & 37.64 & 33.20 & 41.75 & 40.69 & 41.23 \\
\hline
\end{tabular}




\begin{tabular}{|c|c|c|c|c|c|c|c|}
\hline $\begin{array}{c}\text { Average } \\
\text { molecular } \\
\text { formula }\end{array}$ & & $\mathrm{C}_{15.05} \mathrm{H}_{27.61}$ & $\mathrm{C}_{18.68} \mathrm{H}_{34.64} \mathrm{O}_{2}$ & $\mathrm{C}_{4} \mathrm{H}_{10} \mathrm{O}$ & $\mathrm{C}_{12.49} \mathrm{H}_{23.54} \mathrm{O}_{0.023}$ & $\mathrm{C}_{10.59} \mathrm{H}_{20.50} \mathrm{O}_{0.040}$ & $\mathrm{C}_{12.68} \mathrm{H}_{23.91} \mathrm{O}_{0.37}$ \\
\hline $\mathrm{C}(\% \mathrm{wt})$ & & 86.74 & 77.08 & 64.86 & 84.62 & 82.49 & 83.62 \\
\hline H (\%wt) & & 13.26 & 11.92 & 13.52 & 13.29 & 13.31 & 13.14 \\
\hline $\mathbf{O}(\% \mathrm{wt})$ & & 0 & 11 & 21.62 & 2.09 & 4.20 & 3.24 \\
\hline $\begin{array}{c}\text { Molecular weight } \\
(\mathrm{kg} / \mathrm{kmol})\end{array}$ & & 208.20 & 291.26 & 74.12 & 177.13 & 153.98 & 181.96 \\
\hline $\begin{array}{c}\text { Stoichiometric } \\
\text { fuel/air ratio }\end{array}$ & & $1 / 14.51$ & $1 / 12.50$ & $1 / 11.15$ & $1 / 14.18$ & $1 / 13.85$ & $1 / 13.96$ \\
\hline CFPP $\left({ }^{\circ} \mathrm{C}\right)$ & EN 116 & -20 & -1 & $<-51$ & -21 & -20 & -8 \\
\hline $\begin{array}{l}\text { Lubricity (WSD) } \\
(\mu \mathrm{m})\end{array}$ & $\begin{array}{l}\text { EN ISO } \\
12156-1 \\
\end{array}$ & 371.45 & 143 & 571.15 & 419.08 & 435.49 & 267.11 \\
\hline $\begin{array}{c}\text { Derived cetane } \\
\text { number }\end{array}$ & $\begin{array}{c}\text { ASTM } \\
\text { D7668-14 }\end{array}$ & 52.65 & 52.48 & 15.92 & 46.64 & 42.98 & 48.26 \\
\hline Purity & & - & - & 99.5 & - & - & - \\
\hline
\end{tabular}

\subsection{Analytical techniques}

Experimental techniques used for soot characterisation are divided in:

- Structural and morphological techniques: X-Ray Diffraction (XRD), Raman spectroscopy, surface area anlysis (BET analysis), Transmission Electron Microscopy and High-Resolution Transmission Electron Microscopy (TEM and HR-TEM).

- Chemical analysis techniques: X-Ray Photoelectron Spectroscopy (XPS) and Fourier Transform Infrared Spectroscopy (FTIR).

- Thermal analysis techniques: Thermogravimetry Analyser (TGA) and Differential Scanning Calorimetry (DSC).

A X-ray diffractometer from Bruker, model D8 Advance, was used to analyse soot nanostructure. This diffractometer has a $\theta-\theta$ configuration and a radiation source of Cupper-K $\alpha$ with a wavelength of 1.54059 $\AA$. Selected test conditions were $45 \mathrm{kV}$ and $40 \mathrm{~mA}$, the angular interval was varied from 7 to $602 \theta$ degrees from the horizontal level to the vertical $(2 \theta)$. These angles were modified at intervals of $0.012 \theta$ degrees each 3 seconds. The detector of the equipment is LynxEye.

Soot analysis through Raman spectroscopy was carried out using an equipment from Renishaw. The equipment is mainly composed of an optical microscope with white LED illumination (Leica DM2700 M) and with five different lenses, three excitement lasers, a Notch filter and a CCD detector. In this study, the 50x magnification objective (NA 0.75) and the green light laser with a wavelength of $532.1 \mathrm{~nm}$, source power $0.51 \mathrm{~mW}$ (in order to avoid burning the sample), exposure time of $80 \mathrm{~s}$ (divided in four intervals of $20 \mathrm{~s}$ ) were used.

The samples of diesel agglomerates were collected with a thermophoretic sampling device by means of copper grids. The grids were analysed using High-Resolution Transmission Electron Microscopy (HRTEM) with a Phillips CM-200 microscope, with resolution of approximately $2 \AA$ and an accelerating voltage of $200 \mathrm{kV}$.

Surface area and pore volume were analysed using a Gemini V surface area analyser from Micromeritics Instrument Corporation. In these analyses the internal surface area of the samples was measured by isothermal gas adsorption with $\mathrm{N}_{2}$ as adsorptive gas at $77 \mathrm{~K}$ in a liquid nitrogen bath. Previous to the test, the soot sample was degassed at $350{ }^{\circ} \mathrm{C}$ with a $\mathrm{N}_{2}$ flow for 12 hours to remove the moisture and other adsorbed compounds. The surface area was obtained using the Brunnauer-Emmet-Teller (BET) method.

X-Ray Photoelectron Spectroscopy (XPS) measurements of soot surface functional groups were made on an Omicron ESCA+ photoelectron spectrometer using a non-monochromatized MgK $\alpha$ X-Ray source (hv $=1253.6 \mathrm{eV}$ ). Analyzer pass energy of $50 \mathrm{eV}$ was used for survey scans and $20 \mathrm{eV}$ for detailed scans. Binding energies were referenced to the $\mathrm{C} 1 \mathrm{~s}$ peak from adventitious carbonaceous contamination, assumed to have a binding energy of $284.5 \mathrm{eV}$.

A Fourier-Transform Infrared Spectroscopy (FTIR) equipment from Thermo Scientific, model Nicolet 6700 was used to analyse the functional groups of the soot samples. Before the analysis, soot was mixed with $\mathrm{KBr}$ (purchased from Sigma Aldrich as 99\% FTIR grade) by ratio 1000 to 1 due to the strong absorption of the soot sample. Later, the soot-KBr mixture is compressed and then it is ready for analysis. 
A Thermogravimetric Analyser (TGA) from TA Instruments, model Q500, was used to measure the mass loss during the soot oxidation. In this equipment, the sample is located in a crucible inside a small furnace where temperature is variated according to a user-defined programme ${ }^{38}$.

A Differential Scanning Calorimeter (DSC) from TA Instruments, model Q20, was used to measure the heat released during soot oxidation. When soot undergoes a physical or chemical transformation a temperature difference appears between the capsule with the soot sample and an empty capsule use as reference. Temperature difference is related to the heat release by soot sample. The temperature program used in these experiments is the same that the used in the thermogravimetric analysis.

\section{Results and discussion}

\subsection{X-ray diffraction (XRD)}

The X-ray spectra from soot samples tested are shown in Figure 2 a), after translating them vertically to avoid overlap. Different bands were identified and then deconvoluted following the method proposed in Lapuerta et al. ${ }^{15}$, as is shown in Figure 2 b).
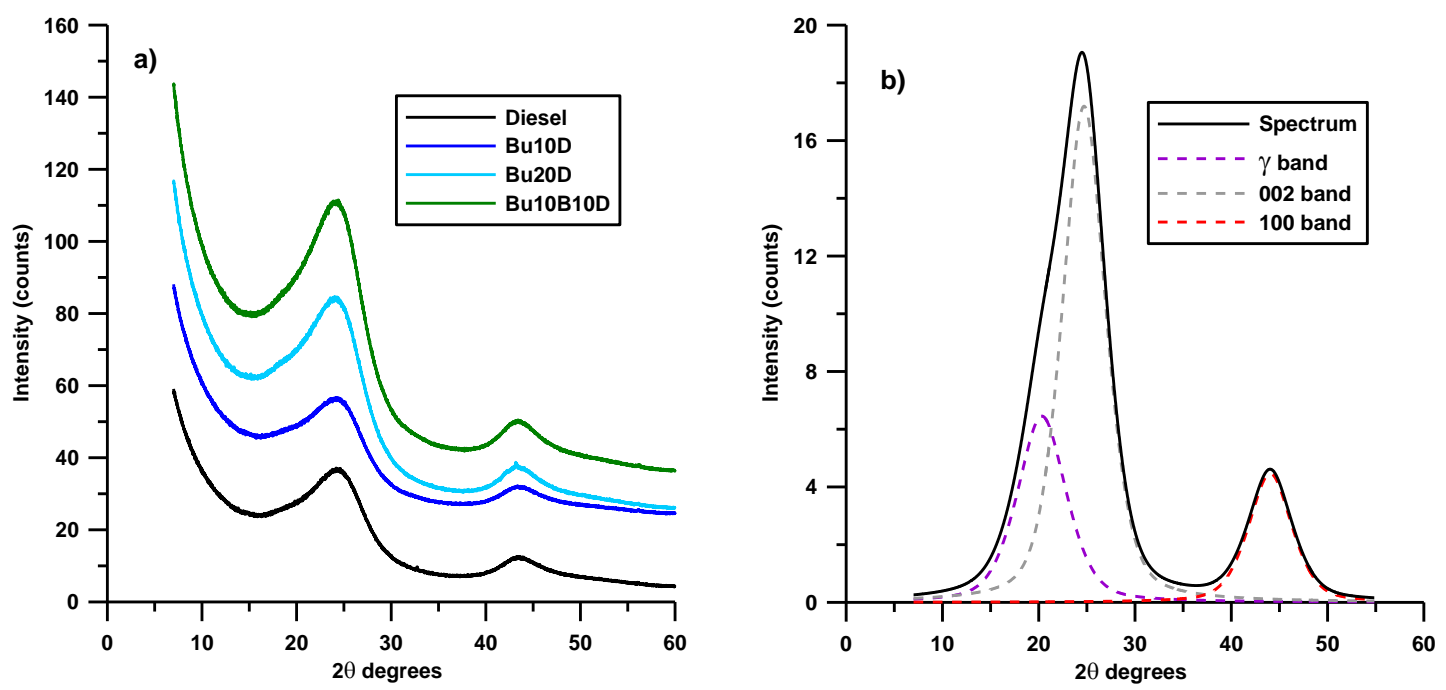

Figure 2: a) X-ray spectra for the soot samples tested. b) Example of deconvolution of the X-ray spectrum.

From the deconvolution of the original spectra and using Bragg and Scherrer equations, different parameters were obtained with the purpose of analysing soot nanostructure. These parameters, which are depicted in Figure 3, are $L_{c}$ (thickness of the graphitic package), $L_{a}$ (length of the graphitic package) and $d_{002}$ (distance between carbon layers). 


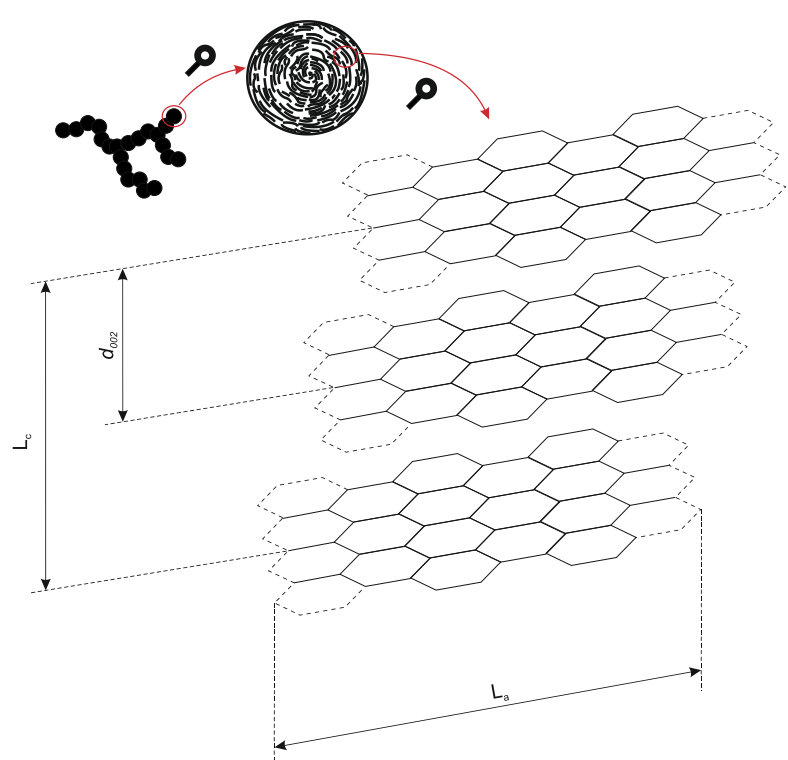

Figure 3: Structural parameters that define soot nanostructure.

Figure 4 shows that the thickness and the length of the graphitic packages are larger for increasing butanol contents, although in some cases the differences observed can not be considered as significant, due to overlap between error bars. Soot generated from butanol blends, mainly Bu20D, shows a structure more ordered than diesel soot, i.e., higher values of stacking thickness and length of the crystallites $\left(L_{c}\right.$ and $L_{a}$ ). Oxygen content in the butanol-diesel blends and in the ternary blend can explain this trend. In the oxidation process, oxygen attacks the active centres in the structural defects, which are more numerous in the short layers than in the large ones. Consequently, these layers are oxidized and disappear due to its small size. For this reason, the average thickness and length of the graphitic packages, which are measured with XRD, increase. This effect can be observed more clearly in Figure 5, in which the nanoestructural parameters $\left(L_{a}\right.$ and $\left.L_{c}\right)$ are represented versus the fuel oxygen content.
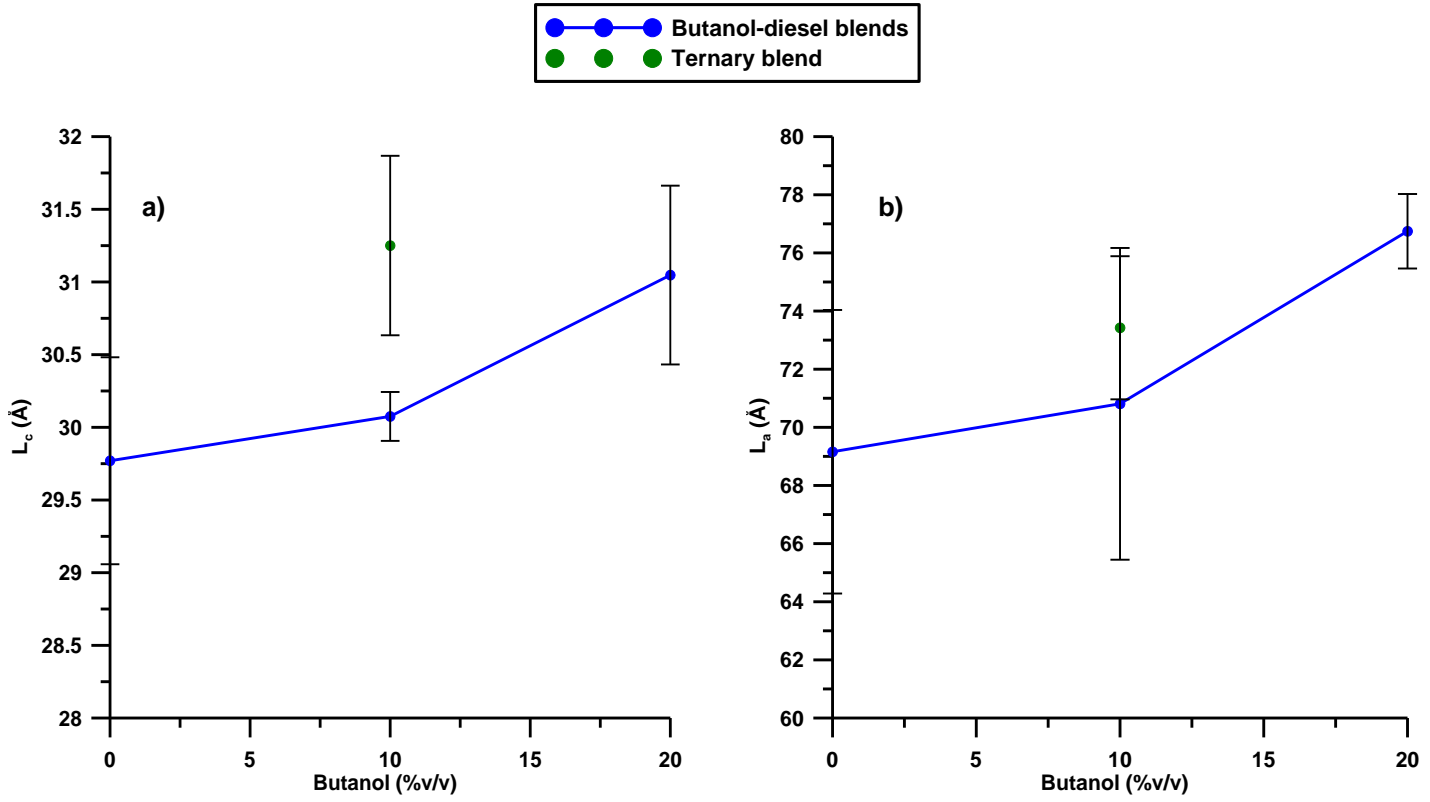

Figure 4: Effect of the butanol content in a) the thickness of the graphitic package and b) the length of the graphitic package.

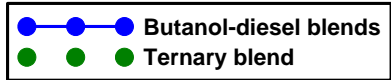



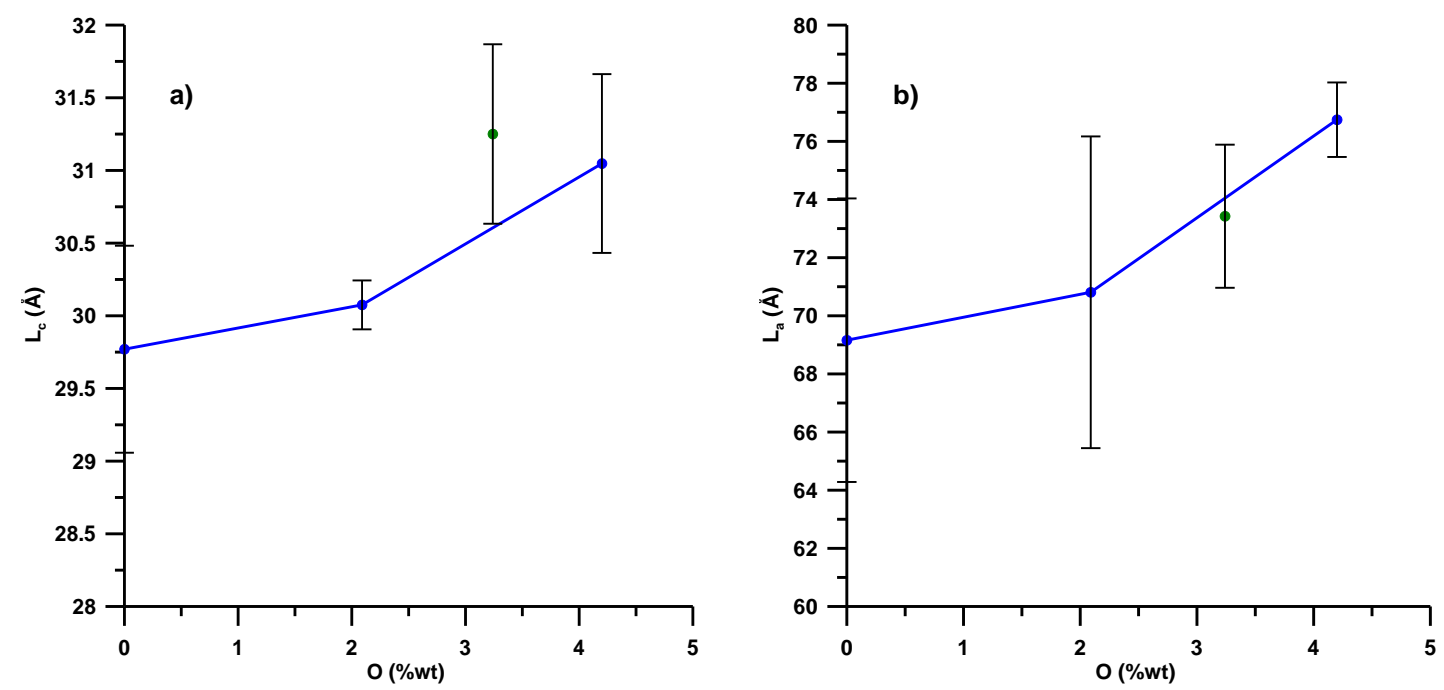

Figure 5:Effect of fuel oxygen content on a) the thickness of the graphitic package and b) the length of the graphitic package.

The effect of butanol content on the interplanar distance of the graphitic layers $\left(d_{002}\right)$ is shown in Figure 6 . As can be observed, butanol content has a negligible effect on this parameter $\left(d_{002}\right)$ since the distance between graphene layers remains constant.

According to different authors ${ }^{22,28}$, the parameters previously studied $\left(L_{a}, L_{c}\right.$, and $\left.d_{002}\right)$ could be related with soot reactivity. The carbon atoms at the edges of the graphene sheets are 100-1000 times more reactive than those in the basal plane because these atoms have higher affinity to form bonds with chemisorbed oxygen due to the availability of unpaired $\mathrm{sp}^{2}$ electrons. For this reason, as the length of the graphitic layers decreases, the atom concentration at the edges of the layers increases. On the other hand, interplanar distance between graphitic lattices $\left(d_{002}\right)$ is related to binding energy of the planes. As $d_{002}$ increases, the binding energy of the planes decreases and, therefore, these planes are less stable and more vulnerable to oxidation. However, to establish the relationship between nanostructure and reactivity, a more complex study must be accomplished.
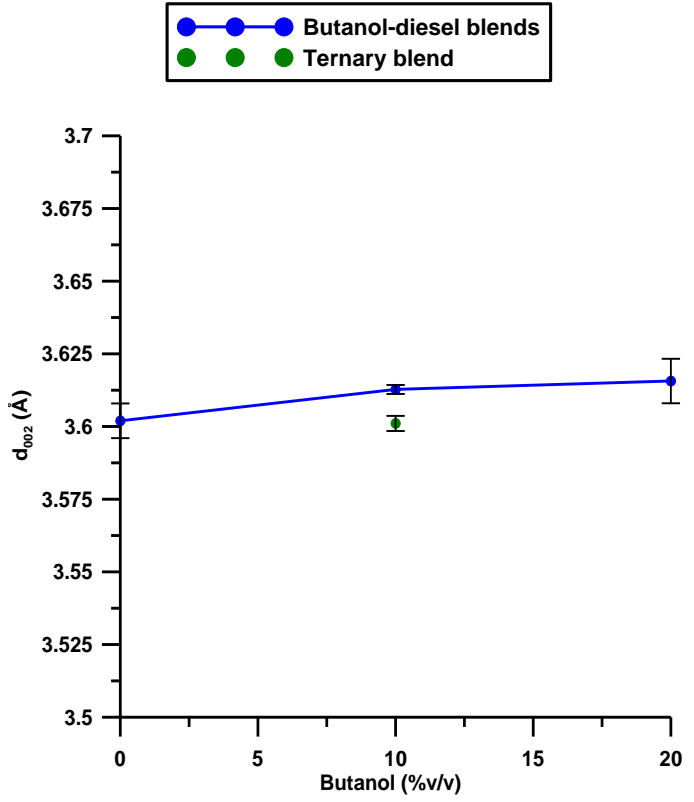

Figure 6: Effect of butanol content on interplanar distance between layers. 


\subsection{Raman spectroscopy}

Raman spectroscopy was used to determine the degree of order of the soot internal structure. Figure 7 a) shows the Raman spectra for soot collected from the butanol blends and the diesel fuel tested. The initial spectra were deconvoluted in different bands ${ }^{39}$. Figure $7 \mathrm{~b}$ ) shows the graphite band $(G)$ and the defect bands $D 1, D 3$ and $D 4$. $G$ band is associated with the order of the soot microstructure. $D 1$ band represents the presence of disorder in the graphitic chain as a consequence of vacancies, crystalline defects and graphene layer edges. D3 band is related to the amorphous carbon associated with functional groups, fragments, or organic molecules. Finally, D4 band is associated with carbon-carbon stretched bonds in the crystalline net such as those of ionic impurities 39,40 .
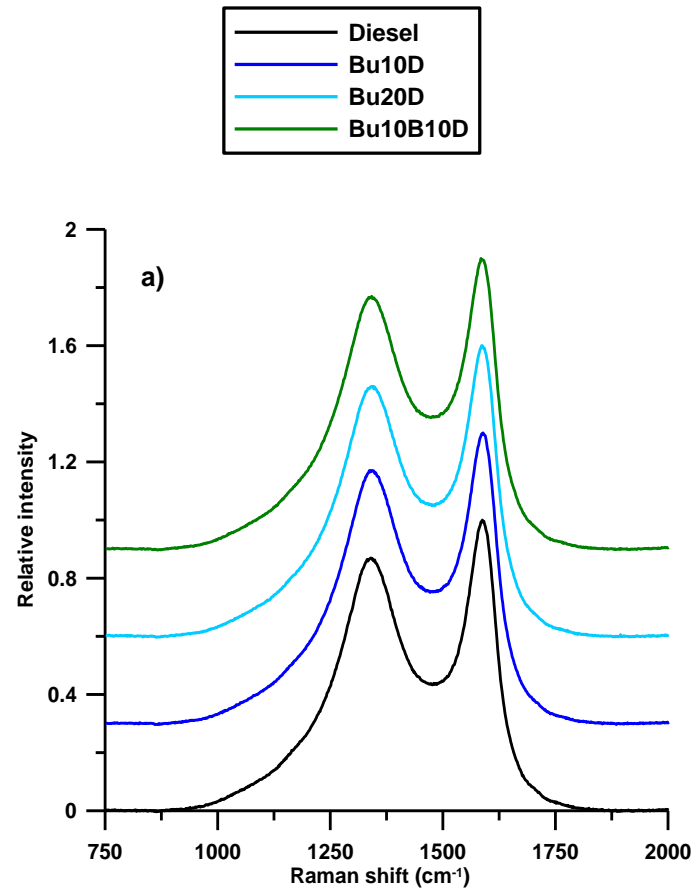
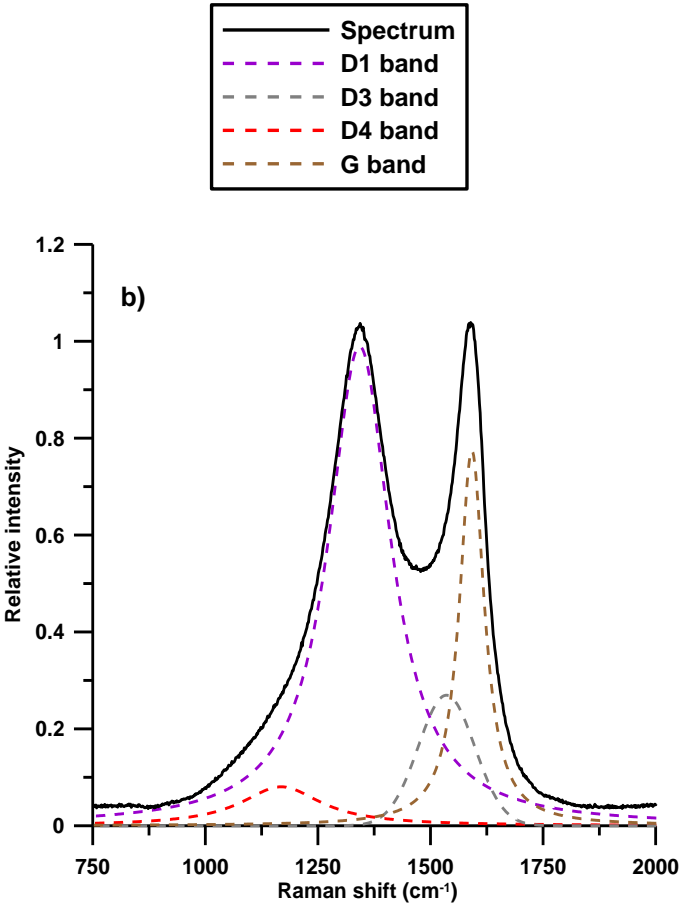

Figure 7: a) Raman spectra for the soot samples tested. b) Example of deconvolution of the Raman spectrum.

The ratio between the peak intensities of $D l$ and $G$ bands was used to evaluate the effect of soot nanostructure, as can be observed in Figure 8. This ratio is related to the structural defects in the basal plane of individual graphene layers ${ }^{15}$. Higher ratios are indicative of higher disorder in soot nanostructure. In the case of soot from butanol blends, as the butanol content increases (from 0 to $10 \% \mathrm{v} / \mathrm{v}$ ), soot nanostructure becomes more disorganized. This behaviour could be explained by the fuel oxygen content, which is not high enough to remove the structural defects. However, as butanol content increases (from 10 to $20 \% \mathrm{v} / \mathrm{v}$ ), soot nanostructure becomes more organized than soot generated from diesel and Bu10D. It may be hipothesized that oxygen in fuel could be high enough to oxydize the structural defects in soot, and for this reason soot nanostructure becomes more ordered. The same behaviour has been observed in other studies with soot generated from diesel-biodiesel blends ${ }^{16,18}$. In case of soot generated from the ternary blend, it is observed that its nanostructure is more organized than soot generated from Bu10D, but it is more disorganized than soot from Bu20D. This trend is consistent with the oxygen content of ternary blend, which is higher than Bu10D but lower than Bu20D. The effect of oxygen fuel content on soot nanostructure is shown in Figure $8 \mathrm{~b}$ ). 

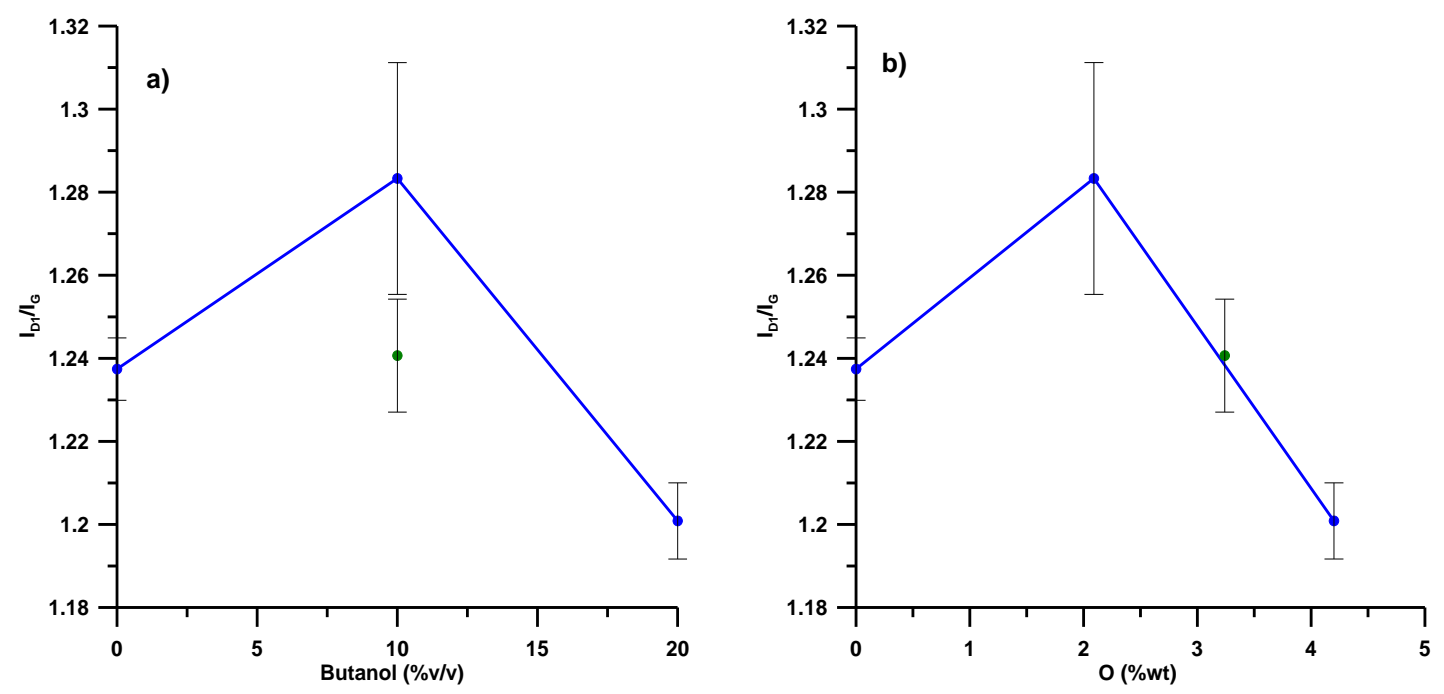

Figure 8: a) Effect of butanol content on the ratio $I_{D I} / I_{G}$. b) Effect of fuel oxygen content on the ratio $I_{D I} / I_{G}$.

\subsection{High-resolution transmission electron microscopy (HR- TEM)}

Detailed images of the soot internal structure, such as those shown in Figure 9 a), were obtained with high-resolution TEM. For statistical analysis, four images were taken for each soot sample, and five different regions from each image were analysed. Finally, the 20 selected regions were artificially magnified using commercial software Image $\mathrm{J}$, and the distance between layers was measured by dividing the stacking thickness of the crystallites by the number of layers Figure $9 \mathrm{~b}$ ).
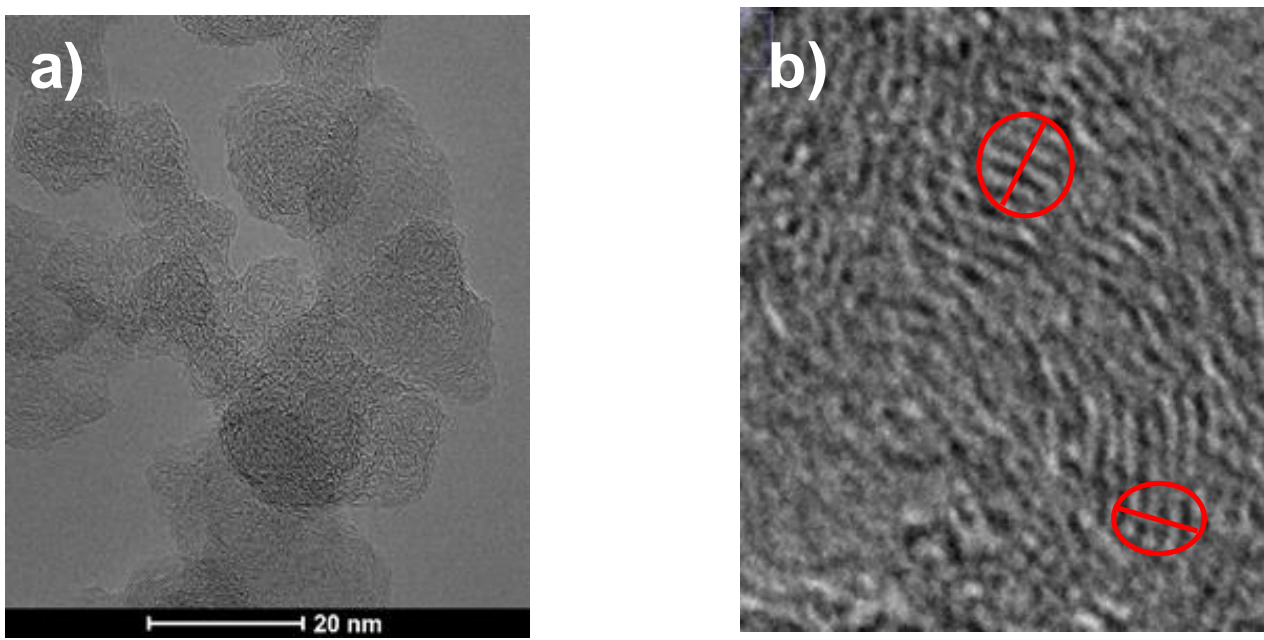

Figure 9: a) HR-TEM images of primary particles. b) Magnification for the measure of the interlayer distance.

In Figure 10, the average interplanar distance is presented for the soot samples studied. This figure shows that the distance between layers is reduced for increasing butanol and oxygen content. Although in some cases the differences in the interplanar distance for the different soot samples can not be considered as significant, due to overlap between error bars, the trend observed is consistent with the results obtained with XRD. According to Belenkov ${ }^{24}$, as the length of the graphitic layers $\left(L_{a}\right)$ increases, the attraction forces between the carbon atoms of adjacent layers (Van der Waals forces) increase, leading to lower distances between layers. 

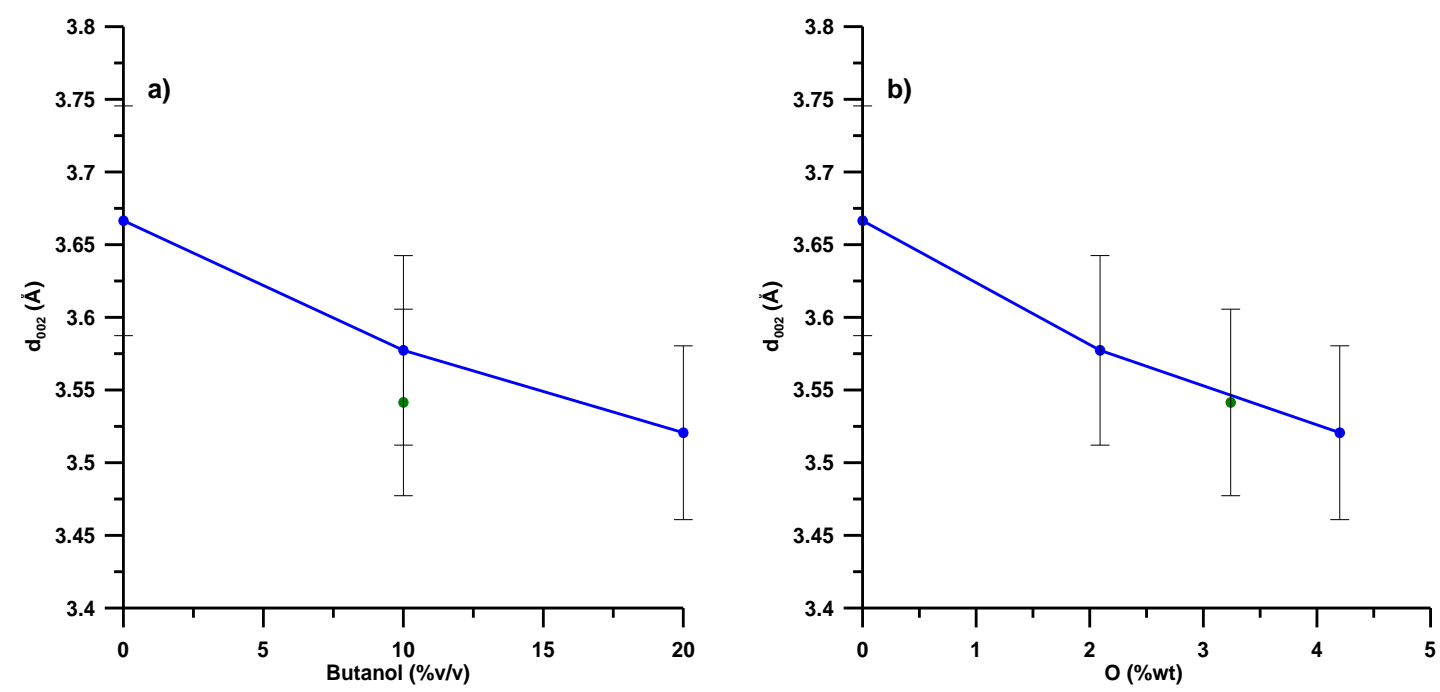

Figure 10: a) Effect of butanol content on interplanar distance measured with HR-TEM. b) Effect of fuel oxygen content on interplanar distance measured with HR-TEM.

There is a numerical discrepancy between the interplanar distance obtained with XRD and HR-TEM, as can be seen when Figure 6 and Figure 10 are compared. It is no clear which technique is more suitable to study soot nanostructure, since both techniques have pros and cons. XRD provides an average value of the characteristics that define soot nanostructure, although, according to different authors ${ }^{41,42}$, the results obtained with this technique (mainly $L_{a}$ ) could be overestimated. On the other hand, HR-TEM examines $\mathrm{d}_{002}$ from a 2D projection of a 3D particle, which can lead to inaccuracies.

\subsection{Low-resolution transmission electron microscopy (LR- TEM)}

Complete images of soot agglomerates (Figure 11) can be obtained with low-resolution TEM. Ten images were captured per each fuel tested and ten primary particle diameters were measured for each image to obtain the primary particle diameter. An average of the 100 diameters measured was calculated for each fuel tested.

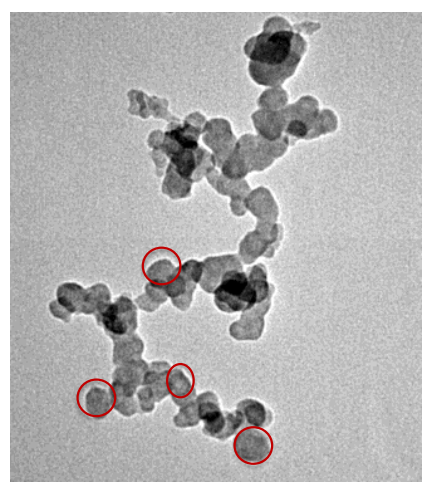

Figure 11: TEM image from primary particle aggregate.

As the butanol content in the blend increases, the oxygen content increases and the aromatic content decreases proportionally. An equilibrium is reached between particle growth and oxidation, leading to stable primary particle sizes. This equilibrium is reached at smaller primary particles as the oxygenated content in the fuel increases (Figure 12), which could be caused either because bond-oxygen and lower aromatic content inhibits particle growth, or because oxygen content enhances soot oxidation, or because of both ${ }^{43}$. In any case, smaller soot particles that have higher surface/volume ratio are expected to increase their reactivity. 

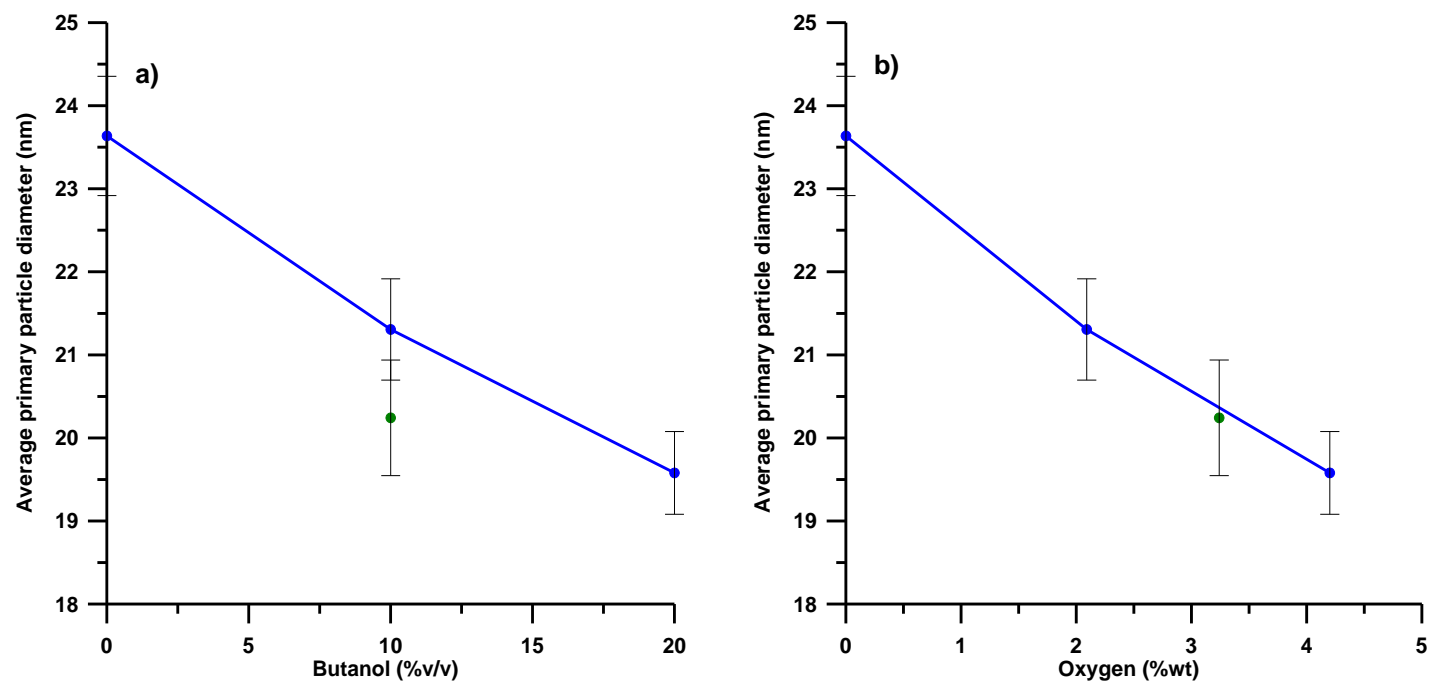

Figure 12: a) Effect of butanol content on the average primary particle diameter. b) Effect of fuel oxygen content on the average primary particle diameter.

\subsection{Surface area analysis}

A typical adsorption isotherm obtained when analysing soot is depicted in Figure 13. Through the shape of the isotherm and according to IUPAC classification ${ }^{44}$, soot samples have a mesoporous structure (pores with diameters between $20 \AA-500 \AA$ ). The hysteresis loop observed is related with the shapes of the pores. According to IUPAC classification, soot samples have slit-shaped pores with parallel walls.

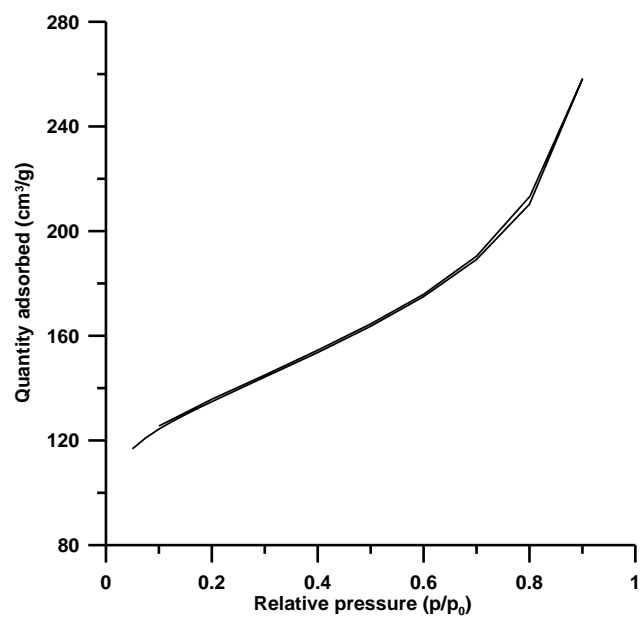

Figure 13: Typical soot adsortion isotherm.

Results obtained when analysing soot surface area are depicted in Figure 14. It can be observed that as the butanol content in the blend increases, soot surface area increases. This result is consistent with the trend observed in Figure 12, since lower primary particle diameters lead to higher surface per unit mass. Again, increased fuel oxygen and decreased aromatic contents could be behind the results obtained. Regarding soot generated from the ternary blend (Bu10B10D), it presents a similar surface area than soot generated from Bu10D. In this case a linear correlation between fuel oxygen content and soot surface area has not been observed. It may be hypothesized that surface area could be related with soot reactivity, since as the surface area increases the oxidant agents have more accessibility to the carbonaceous substrate. 


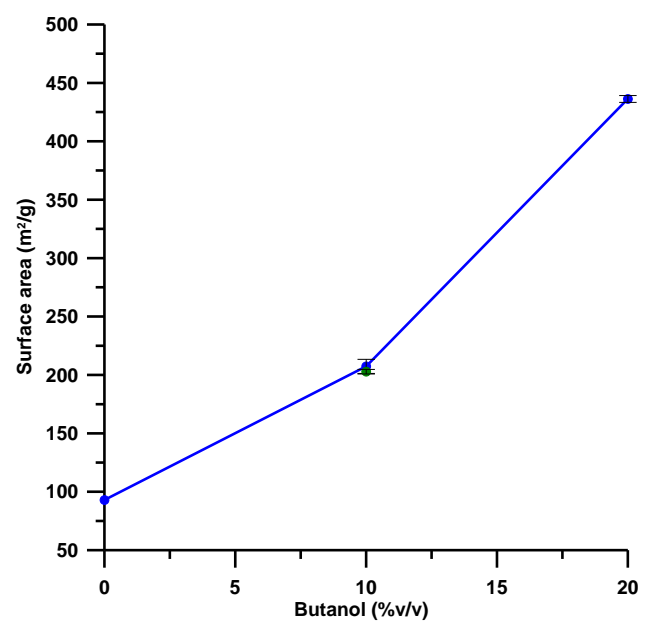

Figure 14: Effect of butanol content on soot surface area.

\subsection{X-ray photoelectron spectroscopy}

Functional groups can be quantified on the soot surface with this technique. Previous to X-ray photoelectron spectroscopy, the derivatisation process is necessary to avoid the uncertainty associated with the deconvolution process of the oxygen and carbon bands in the XPS spectra. This derivatisation process was carried out in a 0.875 litre glass vessel equipped with two valves, under vacuum conditions of approximately $5 \mathrm{~Pa}$ and at $35^{\circ} \mathrm{C}$. The derivatising reagents were located in a beaker located in the centre at the bottom of the vessel. Eight carbon and soot samples were simultaneously located in the interior of some tubes, and all they were also located on an aluminium plate with eight cavities, surrounding the beaker.

Trifluoroacetic anhydride (TFAA) undergoes derivatisation of hydroxyl functional groups existing in the soot surface by esterification, forming an ester on the soot surface and releasing a trifluoroacetic acid molecule ${ }^{29}$. Carboxylic acid groups were derivatised by esterification with trifluoroethanol (TFE) in the presence of 1,3-di-tert-butyl-carbodiimide (DTBC) and pyridine ${ }^{29}$. Carbonyl groups, either from aldehydes or from ketones, were derivatised with trifluoroethyl hydrazine (TFH) in vapour phase ${ }^{29}$. A posterior atomic balance permits quantifying the concentration of the different functional groups, which were present in the original soot.

Figure 15 shows that the oxygen atomic concentration obtained in the soot surface in the form of hydroxyl, carboxyl and carbonyl groups increase for increasing butanol contents, being more apparent for butanol concentrations in fuel higher than $10 \%(\mathrm{v} / \mathrm{v})$. The highest enhancement is observed for the concentration of hydroxyl groups in the blend with $20 \%(\mathrm{v} / \mathrm{v})$ butanol content. This trend is consistent with the presence of a hydroxyl group in the butanol molecule. The oxygen atomic concentration in the form of carboxylic groups also increases with increasing butanol content, especially for alcohol contents higher than $10 \%$ (volume basis). It also increases for the ternary blend, consistently with the presence of carboxylic groups in the biodiesel components of this blend. The oxygen atomic concentration in the form of carbonyl groups shows a slight increase for increasing butanol contents.

From the observed consistency between soot oxygen functional groups and fuel components it can be concluded that much of the oxygen groups detected on the soot surface comes from fuel decomposition rather than being formed during initial stage of soot oxidation.
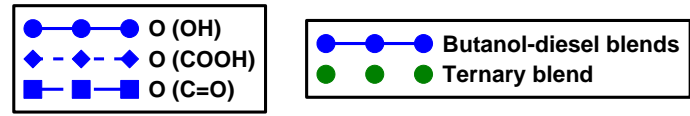


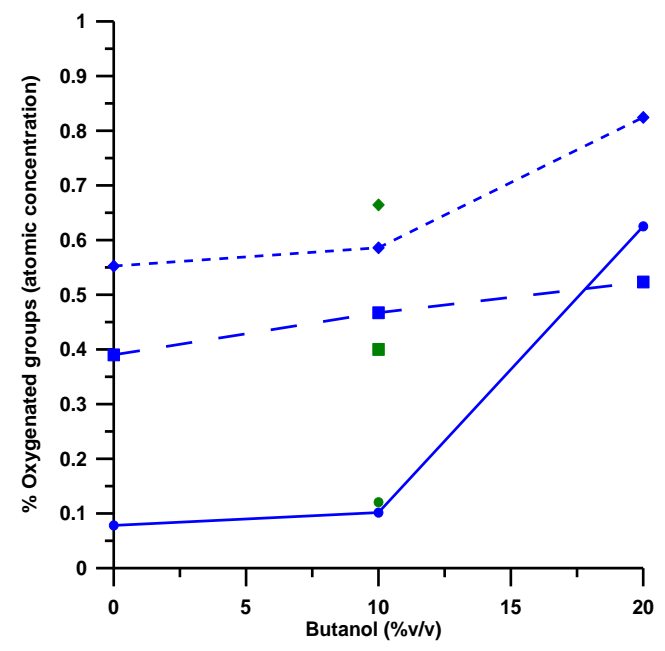

Figure 15: Effect of butanol content on the concentration of oxygenated groups.

\subsection{Fourier-transform infrared spectroscopy (FTIR)}

As in the case of XPS, this technique provides information about functional groups on soot, and therefore, the results obtained are complementary to those obtained with XPS. The FTIR spectra from soot samples tested are shown in Figure 16, after translating them vertically to avoid overlap.

The absorption band between $500-1200 \mathrm{~cm}^{-1}$ corresponds mainly to the bending vibrations of $\mathrm{C}-\mathrm{H}$ bonds of aromatic groups. As can be observed in Figure 16, the band peak is moved towards higher wavenumbers (approximately $1100 \mathrm{~cm}^{-1}$ ) for soot generated from blends with respect to diesel soot. This result could indicate that soot from blends is more oxidised (or could keep more oxygen groups from the oxygenated fuel) than the generated from diesel fuel, since different oxygenated funcionalities show signals for wavenumbers around $1100 \mathrm{~cm}^{-1}$.
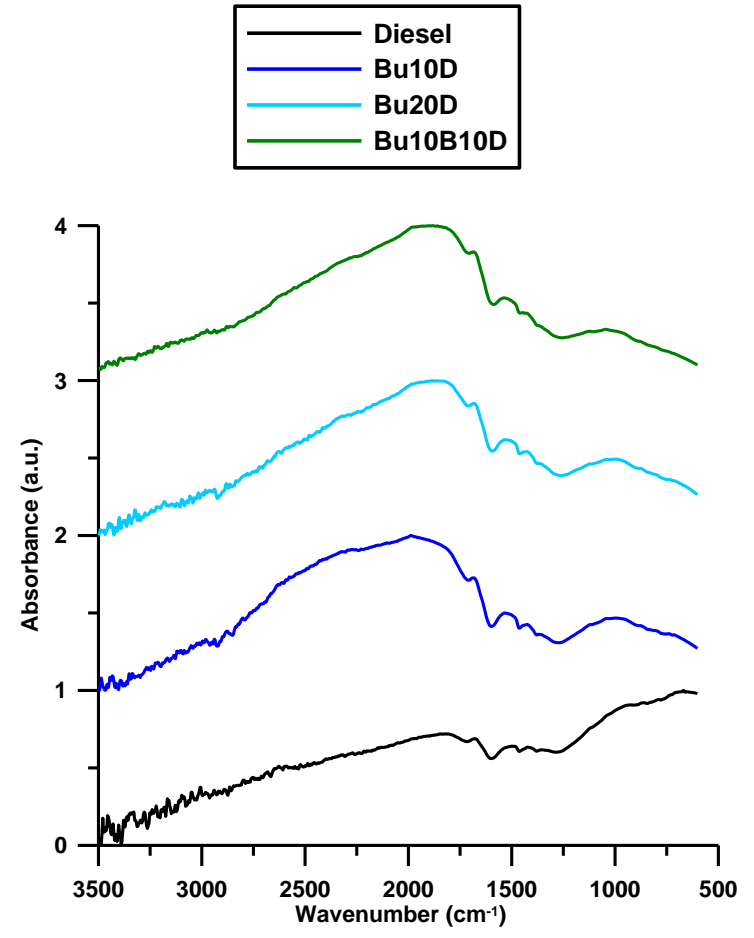

Figure 16: FTIR spectra for soot samples studied.

The second absorption band (1200-1600 $\left.\mathrm{cm}^{-1}\right)$ is originated as a consequence of the bending vibration of $\mathrm{C}-\mathrm{H}$ and $\mathrm{C}-\mathrm{C}$ in aromatics compounds and the stretching vibrations of $\mathrm{C}-\mathrm{O}$ in ethers, esters, alcohols and phenols. These peaks are slightly more significant for soot samples from butanol blends, consistently with 
the results obtained with XPS, showing higher concentration of oxygenated functionalities than the soot generated from diesel fuel. The same trend is observed for the bands between $1600-2000 \mathrm{~cm}^{-1}$, which are attributed to the stress vibrations of the $\mathrm{C}=\mathrm{O}$ bond of the carboxyl groups and of the $\mathrm{C}=\mathrm{C}$ bonds in the aromatic groups.

\subsection{Thermal analysis (TGA and DSC)}

Two typical thermograms obtained with TGA and DSC are shown in Figure 17. The start of oxidation temperature (SOT) is defined as the temperature reached when the $5 \%$ of the initial soot mass is lost or the $5 \%$ of the total heat is released. Finally, $M L R T_{\max }$ and $H R R T_{\max }$ are defined as the temperature at which the maximum mass loss rate is reached or the maximum heat release rate is reached, respectively. These temperatures are good indication of soot reactivity, since the higher the temperatures, the lower the oxidative reactivity of the soot.
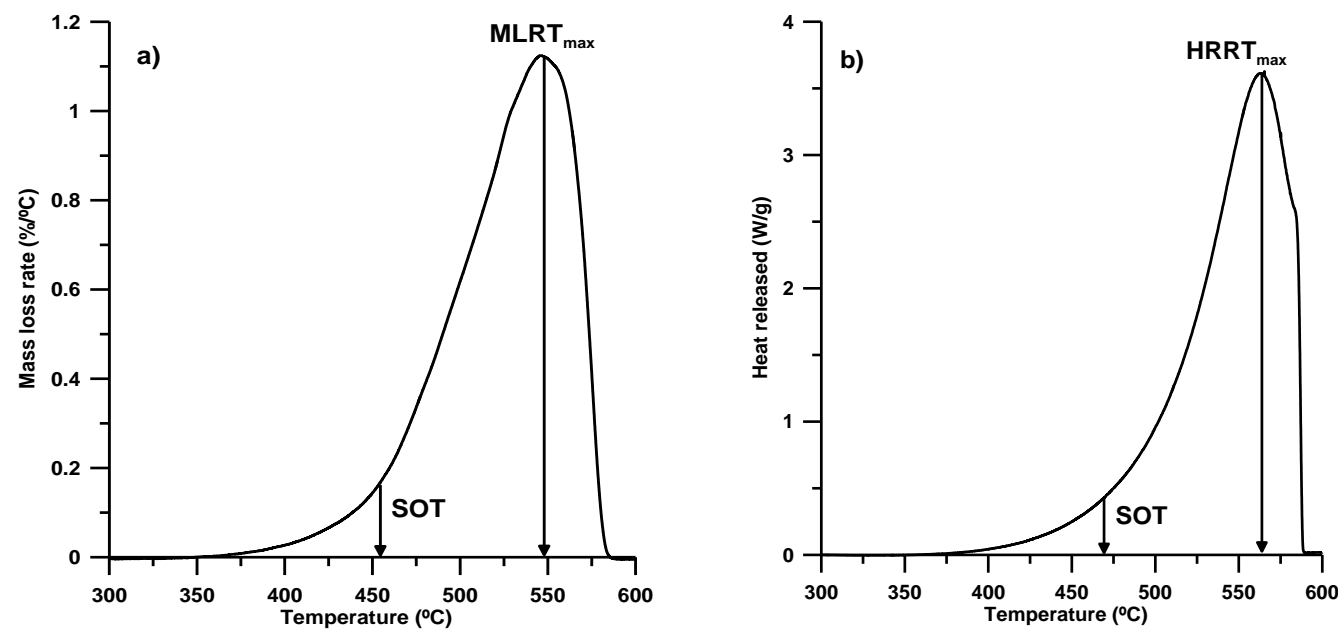

Figure 17: Typical soot oxidation thermograms in a) TGA and b) DSC.

The results obtained are presented in Figure 18, showing that as butanol content increases, the temperatures defined above (SOT, $M L R T_{\max }$ and $H R R T_{\max }$ ) decrease. These results point out higher reactivity of soot generated from butanol blends. This effect is more noticeable for the maximum rate temperatures $\left(M L R T_{\max }\right.$ and $H R R T_{\max }$ ) than for the start of oxidation temperature (SOT). The ternary blend (Bu10B10D) it is even more reactive than Bu20D, despite of its lower oxygen content, suggesting that the oxygen attached to carboxylic groups is more reactive than that attached to hydroxyl groups.

Butanol-diesel blends

- Ternary blend

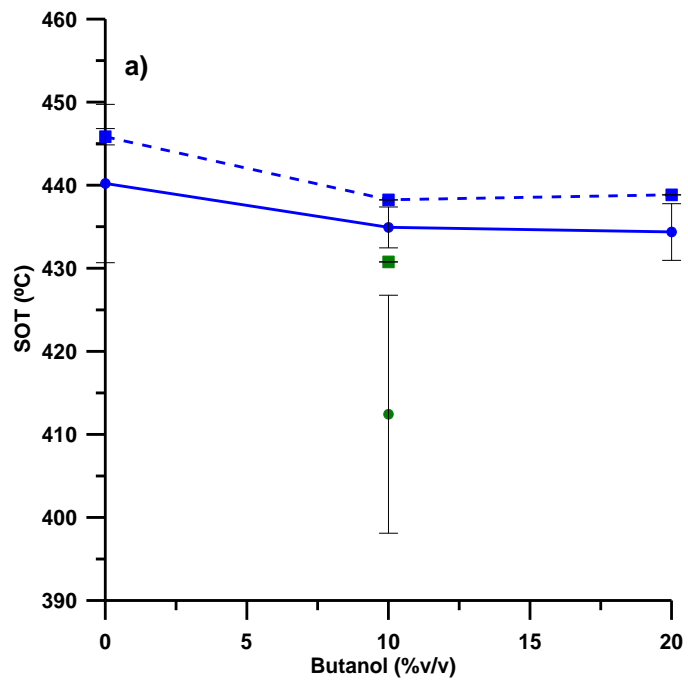

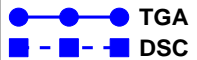

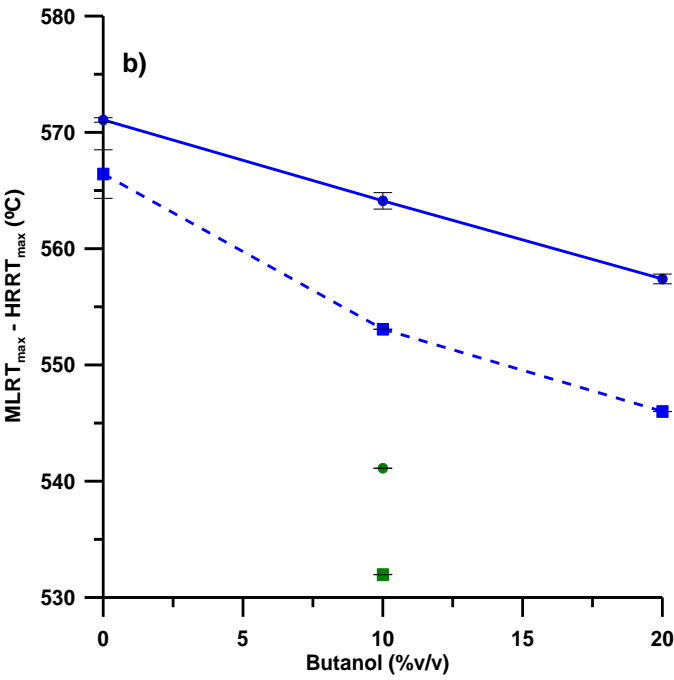


Figure 18: a) Start of oxidation temperature for soot samples tested. b) Temperatures for maximum mass loss rate and heat release rate for soot samples tested.

Soot characteristics evaluated in this study can be related with soot reactivity. As observed above soot nanostructural characteristics, evaluated with XRD, Raman spectroscopy or HR-TEM, did not show a good relationship with its reactivity. The average primary particle diameter is the soot characteristic that best correlates with soot reactivity, with a coefficient of determination equal to 0.63 . Also surface area and concentration of functional groups partially correlate with soot reactivity, although soot from ternary blend did not present neither the highest oxygen concentration nor the highest surface area.

\section{Conclusions}

The following conclusions are obtained from this study:

- From nanostructural analysis it can be concluded that as the butanol content in fuel increases, the degree of order of the soot nanostructure increases. This conclusion can be observed through the study of the parameters obtained with XRD ( $L_{a}$ and $L_{c}$ increases as butanol content increases) and HR-TEM ( $d_{002}$ decreases as butanol content increases). Results obtained with Raman spectroscopy are partially in line with those obtained with XRD and HR-TEM. As the butanol content increases (from 0 to $10 \% \mathrm{v} / \mathrm{v}$ ), soot nanostructure becomes more disorganized (higher $I_{D I} / I_{G}$ ), however, as the butanol content increases from 10 to $20 \% \mathrm{v} / \mathrm{v}$ soot nanostructure becomes more organized (lower $I_{D I} / I_{G}$ ). According to these results, soot generated from butanol blends should be less reactive than that generated from diesel fuel, which is not consistent with the results derived from thermal analysis. Therefore, it can be concluded that soot nanostructure has not a dominant effect on its reactivity.

- Results obtained from structural and morphological techniques (surface area analysis and TEM, respectively) shows that as the butanol (or oxygen) content in fuel increases, soot surface area increases as a consequence of a lower average primary particle diameter. This trend is observed in all cases except for soot from the ternary blend, whose surface area was not observed to increase with respect to the binary blend with equal butanol content. As soot surface area increases the oxidant agents have more accessibility to the carbonaceous matrix and it can be hipothesized that soot becomes more reactive, which is in line with the results obtained with thermal analysis techniques.

- With regard to the results obtained with chemical analysis techniques (XPS and FTIR), it can be observed that as butanol content increases, oxygenated functional groups on soot surface increases. It can be concluded that much of the oxygen groups detected on the soot surface comes from fuel decomposition rather than being formed during initial stage of soot oxidation.

- The results obtained with thermal analysis techniques (TGA and DSC) show that soot generated from butanol blends is more reactive than that generated from diesel fuel. The soot from the ternary blend is observed to be more reactive than soot from $\mathrm{Bu} 20 \mathrm{D}$, proving that the oxygen attached to carboxylic groups also contributes to increase the soot reactivity.

- Among all the techniques used in this study, XRD, Raman spectroscopy and HR-TEM, did not show a good relationship with its reactivity, whereas the average primary particle diameter, the surface area and the concentration of functional groups partially correlated.

\section{Acknowledgements}

This research was funded by the European Union Horizon 2020 Research and Innovation Programme under grant agreement $n^{\circ} 640462$ (ButaNexT project). Nissan, Repsol and Green Biologics are gratefully acknowledged for the donation of the vehicle, the diesel fuel, and the n-butanol fuel, respectively. Junta de Comunidades de Castilla-La Mancha is also acknowledged for financing the fellowship of Jesús Sánchez-Valdepeñas. T. G. would also like to thank the Regional Government of Aragon (DGA) for the support provided under the research groups support programme.

\section{References}

(1) Pourazar, J.; Frew, A. J.; Blomberg, A; Helleday, R.; Kelly, F. J.; Wilson, S. Diesel exhaust exposure enhances the expression of IL-13 in the bronchial epithelium of healthy subjects. Resp. Med. 2004, 98, 821-825. 
(2) Goyal, P.; Jaiswal, N.; Kumar, A.; Dadoo, J. K.; Dwarakanath, M.; Air quality impact assessment of $\mathrm{NO}_{\mathrm{x}}$ and PM due to diesel vehicles in Delhi. Transport. Res. D-Tr. E. 2010, 15, 298-303.

(3) Okui, N.; Kobayashi, M.; A study on hybrid control method for improvement of fuel economy and exhaust-gas emission of hybrid trucks. SAE. J-Automot. Eng. 2015-01-1780.

(4) UN, 2008 Commission Regulation (EC) No 692/2008 of 18 July 2008 implementing and amending Regulation (EC) No 715/2007 of the European Parliament and of the Council on typeapproval of motor vehicles with respect to emissions from light passenger and commercial vehicles (Euro 5 and Euro 6) and on access to vehicle repair and maintenance information (OJ L 199 28.7.2008, p.1).

(5) Proposal for a Directive of the European Parliament and of the Council on the promotion of the use of energy from renewable sources (recast). (RED-II COM767). 2017.

(6) Shamum, S.; Belgiorno, G.; Di Blasio, G.; Beatrice, C.; Tunér, M.; Tunestål, P. Performance and emissions of diesel-biodiesel-ethanol blends in a light duty compression ignition engine. Appl. Therm. Eng. 2018, 145, 444-452.

(7) Lapuerta, M.; Armas, O.; García-Contreras R. Effect of ethanol on blending stability and diesel engine emissions. Energ. Fuel. 2009, 23, 4343-4354.

(8) Lapuerta, M.; Hernández, J. J.; Fernández-Rodríguez, D.; Cova-Bonilla, A. Autoignition of blends of n-butanol and ethanol with diesel or biodiesel fuels in a constant-volume combustion chamber. Energy. 2017, 118, 613-621.

(9) Lapuerta, M.; Rodríguez-Fernández, J.; Fernández-Rodríguez, D.; Patiño-Camino R. Modelling viscosity of butanol and ethanol blends with diesel and biodiesel fuels. Fuel. 2017, 199, 332-338.

(10) Grisales, V.; Olivar, G. Butanol production from lignocellulose by simultaneous fermentation, saccharification and pervaporation or vacuum evaporation. Bioresource. Technol. 2016, 218, 174182.

(11) Han, X.; Yang, Z.; Wang, M.; Tjong, J.; Zheng, M. Clean combustion of n-butanol as a next generation biofuel for diesel engines. Appl. Energ. 2017, 198, 347-359.

(12) Kumar, M.; Gayen, K. Developments in biobutanol production: New insights. Appl. Energ. 2011, 88, 1999-2012.

(13) Green, E. M. Fermentative production of butanol - the industrial perspective. Curr. Opin. Biotech. 2011, 22, 337-343.

(14) Forzatti, P.; Lietti, L.; Nova, I.; Tronconi, E. Diesel NOx aftertreatment catalytic technologies: Analogies in LNT and SCR catalytic chemistry. Catal. Today. 2010, 151, 202-211.

(15) Lapuerta, M.; Oliva, F.; Agudelo, J. R.; Boehman, A. L. Effect of fuel on the soot nanostructure and consequences on loading and regeneration of diesel particulate filters. Combust. Flame. 2012, $159,844-853$.

(16) Song, A.; Alam, M.; Boehman, A. L. Impact of alternative fuels on soot properties and DPF regeneration. Combust. Sci. Technol. 2007, 179, 1991-2037.

(17) Soriano, J. A.; Agudelo, J. R.; López, A. F.; Armas, O. Oxidation reactivity and nanostructural characterization of the soot coming from farnesane - A novel diesel fuel derived from sugar cane. Carbon. 2017,125, 516-529.

(18) Ye, P.; Sun, C.; Lapuerta, M.; Agudelo, J. R.; Vander Wal, R. L.; Boehman, A. L.; Toops, T. J.; Daw, S. Impact of rail pressure and biodiesel fueling on the particulate morphology and soot nanostructures from a common-rail turbocharged direct injection engine. Int. J. Engine. Res. 2014, 17, 193-208.

(19) Mühlbauer, W.; Zöllner, C.; Lehmann, S.; Lorenz, S.; Brüggemann, D. Correlations between physicochemical properties of emitted diesel particulate matter and its reactivity. Combust. Flame. 2016, 167, 39-51.

(20) Ruiz, F. A.; Cadrazco, M.; López, A. F.; Sánchez-Valdepeñas, J.; Agudelo, J. R. Impact of dualfuel combustion with n-butanol or hydrous ethanol on the oxidation reactivity and nanostructure of diesel particulate matter. Fuel. 2015, 161, 18-25. 
(21) Bhardwaj, O. P.; Lüers, B.; Holderbaum, B.; Koerfer, T.; Pischinger, S.; Honkanen, M. Utilization of HVO fuel properties in a high efficiency combustion system: Part 2: Relationship of soot characteristics with its oxidation behaviour in DPF. SAE. J-Automot. Eng. 2014-01-2846.

(22) Al-Qurashi, K.; Boehman, A. L. Impact of exhaust gas recirculation (EGR) on the oxidative reactivity of diesel engine soot. Combust. Flame. 2008, 155, 675-695.

(23) Happonen, M.; Lähde, T.; Messing, ME.; Sarjovaara, T.; Larmi, M.; Wallenberg, L. R.; Virtanen, A.; Keskinen, J. The comparison of particle oxidation and surface structure of diesel soot particles between fossil fuel and novel renewable diesel fuel. Fuel. 2010, 89, 4008-4013.

(24) Belenkov, E. A. Formation of graphite structure in carbon crystallites. Inorg. Mater. 2001, 37, 928934.

(25) Wang, L.; Song, C.; Song, J.; Lv, G.; Pang, H.; Zhang, W. Aliphatic C-H and oxygenated surface functional groups of diesel in-cylinder soot: Characterizations and impact on soot oxidation behaviour. P Combust Inst 2013, 34, 3099-3106.

(26) Lapuerta, M.; Rodríguez-Fernández, J.; Sánchez-Valdepeñas, J.; Salgado, M. S. Multi-technique análisis of soot reactivity from conventional and paraffinic diesel fuels. Flow. Turbul. Combust. 2016, 96, 327-341.

(27) Gargiulo, V.; Alfè, M.; Di Blasio, G.; Beatrice, C. Chemico-physical features of soot emitted from a dual-fuel ethanol-diesel system. Fuel. 2015, 150, 154-161.

(28) Yehliu, K.; Vander Wal, R. L.; Armas, O.; Boehman, A, L. Impact of fuel formulation on the nanostructure and reactivity of diesel soot. Combust. Flame. 2012, 159, 3597-3606.

(29) Langley, L. A.; Villanueva, D. E.; Fairbrother, D. H. Quantification of surface oxides on carbonaceous materials. Chem. Mater. 2006, 18, 169-178.

(30) Liati, A.; Spiteri, A.; Eggenschwiler, A. D.; Vogel-Schäuble, N. Microscopic investigation of soot and ash particulate matter derived from biofuel and diesel: implications for the reactivity of soot. J. Nanopart. Res. 2012, 14, 1224.

(31) Luo, C., Lee, W.; Liaw, J. Morphological and semi-quantitative characteristics of diesel soot agglomerates emitted from commercial vehicles and a dynamometer. J. Environ. Sci. 2009, 21, 452-457.

(32) Ma, Y.; Zhu, M.; Zhang, Z.; Zhang, D. Effect of a homogeneous combustion catalyst on the nanostructure and oxidative properties of soot from biodiesel combustion in a compression ignition engine. P. Combust. Inst. 2015, 35, 1947-1954.

(33) Fernandes, M. B.; Skjemstad, J. O.; Johnson, B. B.; Wells, J. D.; Brooks, P. Characterization of carbonaceous combustion residues. I. Morphological, elemental and spectroscopic features. Chemosphere. 2003, 51, 785-795.

(34) Braun, A.; Huggins, F. E.; Shah, N.; Chen, Y.; Wirick, S.; Mun, S. B.; Jacobsen, C.; Huffman, G. P. Advantages of soft X-ray absorption over TEM -EELS for solid carbon studies - a comparative study on diesel soot with EELS and NEXAFS. Carbon. 2005, 43, 117-124.

(35) Agudelo, J. R.; Álvarez, A.; Armas, O. Impact of crude vegetable oils on the oxidation reactivity and nanostructure of diesel particulate matter. Combust. Flame. 2014, 16, 2904-2915.

(36) Directive 28/2009/CE of the European Parliament and of the Council (2009)

(37) Lapuerta, M.; Ramos, A.; Barba, J.; Fernández-Rodríguez, D. Cold- and warm-temperature emissions assessment of n-butanol blends in a Euro 6 vehicle. Appl. Energ. 2018, 218, 173-183.

(38) Rodríguez-Fernández, J.; Oliva, F.; Vázquez, R.A. Characterization of the diesel soot oxidation process through an optimized thermogravimetric method. Energ. Fuel. 2011, 25, 2039-2048.

(39) Lapuerta, M.; Oliva, F.; Agudelo, J. R.; Stitt, J. P. Optimization of Raman spectroscopy parameters for characterizing soot from different diesel fuels. Combust. Sci. Technol. 2011, 183, 1203-1220.

(40) Sadezky, A.; Muckenhuber, H., Grothe, H.; Niessner, R.; Pöschl, U. Raman microspectroscopy of soot and related carbonaceous materials: Spectral analysis and structural information. Carbon. 2005, 43, 1731-1742. 
(41) Short, M. A.; Walker, P. L. Measurement of interlayer spacings and crystal sizes in turbostratic carbons. Carbon. 1963, 1, 3-9.

(42) Guerrero Peña, G. D. J.; Raj, A.; Stephen, S.; Anjana, T.; Hammid, Y. A.; Brito, J. L.; Al Shoaibi, A. Physicochemical properties of soot generated from toluene diffusion flames: Effects of fuel flow rate. Combust. Flame. 2017, 178, 286-296.

(43) Kholghy M. R.; Weingarten, J.; Sediako, A.D.; Barba, J.; Lapuerta, M.; Thompson, M. J. Structural effects of biodiesel on soot formation in a coflow diffusion flame. P. Combust. Inst. 2017, 36, 1321-1328.

(44) Alothman, Z. A. A review: Fundamental aspects of silicate mesoporous materials. Materials. 2012, 5, 2874-2902. 